\title{
Potencial impacto de la nueva legislación en la investigación biomédica en Chile
}

\section{Potential impact of the new Chilean legislation in the biomedical research}

La entrada en vigencia a contar del $1^{\circ}$ de octubre de 2012, de la nueva normativa legal sobre derechos y deberes de los pacientes -Ley 20.584- ${ }^{1}$, nos invita a reflexionar si se avala a quienes participan como probandos en investigación científica, que esta se ajusta a estándares éticos internacionales, lo que se deriva en garantizar el respeto de los Derechos Humanos de los sujetos probandos ${ }^{2}$, responsabilidad esencial de los Comités Ético-Científicos cuyo mandato legal es proteger los derechos, seguridad y bienestar* de los sujetos de investigación, según señala en su artículo 16 el reglamento de la Ley $20.120^{4,5}$.

El reconocimiento de que la persona humana es portadora de una dignidad irrenunciable, es un fundamento de validez universal para exigir a la sociedad el respeto de la libertad e igualdad de derechos de todos los seres humanos. En el ámbito de la investigación en la cual participan personas, ello se materializa en la protección de la vida, de la integridad fisica y psíquica y del bienestar de los sujetos que participan en ensayos clínicos.

La moral aconseja guardar el debido respeto a la dignidad humana, a los derechos humanos y a las libertades fundamentales en los ensayos clínicos, para que éstos resulten comprensibles a la humanidad. Por otra parte, el desarrollo científico y tecnológico, ha generado un desfase entre las normas morales y la capacidad de actuar del hombre. Lo anterior requiere de deberes mínimos vinculantes para conciliar las diferencias valóricas, razón principal o motivo con que se pretende afianzar y asegurar a las normas jurídicas; $y$ de máximas morales recomendadas por las declaraciones y documentos internacionales, que tratan de cuestiones éticas relacionadas con la medicina, impartiendo orientaciones para las decisiones o prácticas en los ensayos clínicos, que promuevan el respeto a la dignidad humana y que pongan de manifiesto cómo la ética da cuenta de la razón filosófica de la moral en su especificidad, es decir, ¿Por qué debo?, sin verse obligado a limitarse a una moral determinada o el ¿Qué debo hacer? sólo para ajustar la decisión o práctica a la norma jurídica. La experiencia ha conducido a que la comunidad médica y autoridades competentes, elaboren normas para la realización de ensayos clínicos, estableciendo estándares éticos que prevengan esta última conducta.

En este sentido, cabe preguntarse si nuestra legislación se ajusta a estos estándares, si acoge la obligación de cuidado del paciente, el derecho a la protección de la salud y la compensación de los sujetos perjudicados.

Las declaraciones internacionales y el ordenamiento jurídico vigente en nuestro país, tienen en común el bienestar del individuo, por sobre el interés del investigador ${ }^{2}$, por lo que no es suficiente que el participante esté informado y otorgue su consentimiento favorable para participar en investigación para que una investigación se ajuste a estándares internacionalmente compartidos. En este sentido, la protección del bienestar tiene alcances que van más allá de la capacidad del individuo de consentir, pues se encuentra vinculada a la información que se entregue, así como a los resguardos necesarios para precaver daño y en caso de que este se produzca, de su debida reparación ${ }^{6}$.

De ahi la inquietud frente al nuevo escenario dado por la nueva legislación ${ }^{1,4,5}$, en materias relacionadas a las limitaciones del uso de la información contenida en la ficha clínica, la participación en investigación de quienes sufren discapacidades o no son absolutamente capaces y el resguardo de los

\footnotetext{
*Bienestar ( $3^{\text {a }}$ acepción): "Estado de la persona en el que se le hace sensible el buen funcionamiento de su actividad somática y psíquica"3.
} 
derechos de los sujetos; temas que deben ser abordados, no sólo desde la capacidad de consentir del individuo, sino que se deben incorporar otros aspectos como lo son el seguimiento del desarrollo o ejecución de la investigación y la resolución de los eventos adversos que se presenten. Si bien es cierto que se establecen limitaciones a la capacidad de realizar investigación en sujetos que no poseen la plena capacidad psíquica o intelectual, y por ende tampoco la capacidad legal, no se debe olvidar, que los Derechos Humanos, -dentro de los cuales, se encuentra el derecho a la protección de la salud, y el libre e igualitario acceso a las acciones de salud-, se encuentran garantizados en nuestro orden jurídico nacional, en el artículo 19 número 9, de la Constitución Política, la cual es una norma de primer orden jerárquico y base del ordenamiento jurídico nacional, dentro del cual se inserta el derecho sanitario y las políticas públicas de salud.

Para garantizar el derecho a la protección de la salud, se requiere que nuestro país sea generador de conocimiento de acuerdo a nuestras propias necesidades como país y en interés de quienes participan en la investigación científica, de ahi la importancia de conciliar el respeto de los derechos humanos de todos los individuos, como lo sostiene la Constitución de la República en su artículo 1, que señala que las personas nacen libres e iguales en dignidad y derechos, con lo señalado en su artículo $N^{\circ} 19$ sobre el derecho de todas las personas a la protección de la salud y acceso a las acciones de salud. Por ello el bienestar de quienes participan en investigación, debe estar garantizado mediante estándares éticos compartidos internacionalmente, dentro de los cuales se encuentra el "consentimiento informado", como también el resguardo de los sujetos que participan en investigación ${ }^{2}$.

Desde el punto de vista de la bioética se ha propuesto el cumplimiento de siete principios para que una investigación sea éticamente aceptable. Según estos principios la investigación debe: a) tener valor social o científico; b) tener apego riguroso a la metodología cientifica; c) contar con una selección equitativa de los voluntarios según los objetivos cientificos, debiendo especificar las comunidades seleccionadas, los lugares de estudio y los criterios de inclusión para enrolar a los voluntarios; d) tener una relación riesgo/beneficio favorable: en el contexto de los estándares de la práctica clínica y del protocolo de investigación, los beneficios potenciales para el individuo y la sociedad deben exceder a los riesgos; e) Contar con una evaluación independiente realizada por un Comité de Ética que la apruebe; f) contar con un consentimiento informado individual que garantice la participación completamente libre e informada de cada participante y g) tener respeto a los voluntarios participantes, que les permita mantener su privacidad, ser monitoreados adecuadamente y retirarse en cualquier momento de la investigación sin dar explicaciones y sin ser sancionados por esta determinación. Estos principios si bien son universales, deben adaptarse según las condiciones sanitarias, económicas, culturales y tecnológicas en que se está llevando a efecto la investigación clínica'.

Por su parte el ordenamiento jurídico, asegura a todas las personas, la igual protección en el ejercicio de sus derechos, pero en ciertas situaciones expresamente señaladas en la ley, impone un estándar de exigencia mayor, donde no basta el consentimiento de quien es relativa o absolutamente incapaz, materia resuelta jurídicamente a través de la representación, para asegurar la protección de estas personas, pues el representante se encuentra obligado a emplear el cuidado necesario que otorgue garantía de la debida protección de los derechos de su representado, y en este sentido debe resguardar que terceros y la sociedad respeten los derechos de quienes no son absolutamente capaces, dentro de los cuales se encuentra el derecho a la protección de la salud.

Cuando el Derecho declara incapaz de manera absoluta o relativa a una persona, no busca con ello desconocer o limitar los derechos de ésta, sino que por el contrario, busca entregar una especial protección a quienes no son plenamente capaces, con el objeto que sus derechos no sean vulnerados o violados. Por ello mediante la figura jurídica de la representación, regulada en nuestro código civil, se entrega a un tercero, conforme al artículo 1.448 de este código, la capacidad de ejercicio sobre los derechos que el incapaz goza o posee, para su debido ejercicio.

Así, en materia sanitaria, lo que busca el legislador, es evitar actos u omisiones arbitrarios e ilegales que atenten contra los derechos de los relativa o absolutamente incapaces, por lo que se debe tener especial cuidado en el ejercicio de sus derechos. Una manera de lograr ello es mediante dos condiciones: la primera una mayor exigencia en la capacidad para consentir en la figura jurídica de la 
representación y la segunda una especial garantía de la reparación del daño; pero ello en ninguna circunstancia debe ser interpretado como una limitación o perturbación en el ejercicio de derechos, pues ello se traduce en la imposibilidad de acceder por parte de ellos a la debida protección de su salud.

Las acciones de salud, requieren ser permanentemente revisadas y actualizadas mediante politicas y programas públicos de salud, basados en nuevos antecedentes y conocimientos, por lo que una limitación en la generación del conocimiento necesario que no permita proteger la salud de las personas, $o$ limite el acceso de quienes no son plenamente capaces a dichas acciones de salud o a acciones propias para su discapacidad, resulta contrario a los derechos humanos y a nuestro ordenamiento jurídico, y ello no representa el espíritu de la ley, que otorga un especial cuidado o protección a quienes se encuentran en esta situación.

La preocupación que se ha generado es producto de las nuevas normas jurídicas que rigen esta materia ${ }^{8}$, un ejemplo de ello es el artículo 28 de la ley 20.584 que "Regula los Derechos y Deberes que tienen las personas en relación con acciones vinculadas a su atención en salud”, si bien su lectura literal puede ser interpretada de manera textual y aislada, con la consecuente desprotección de quienes poseen discapacidad psíquica o intelectual, debería ser interpretado de manera inclusiva dentro de un orden jurídico que asegura el derecho a la protección de la salud de todas las personas, independiente de su condición, lo contrario constituye una limitación a las garantías esenciales de los derechos humanos y garantizadas en nuestro orden jurídico.

No obstante las consideraciones precedentes, los miembros de diversos comités de ética de investigación en seres humanos de diferentes instituciones han manifestado que el nuevo cuerpo legal-Ley 20.584- impone algunas limitaciones a la investigación en seres humanos, que de no ser corregidas, representarán paradojalmente un potencial perjuicio para aquellos que la nueva normativa legal intenta precisamente proteger 9 .

Básicamente se han señalado dos temas en los cuales la actual legislación tendría un potencial impacto altamente negativo. El primero de ellos es la que se expresa en el artículo 23 de la ley 20.584 en que establece la prohibición de participar en investigaciones cientificas cuando la persona con discapacidad psíquica o intelectual no pueda expresar su voluntad. Esta disposición ha sido entendida en el sentido que imposibilita efectuar investigación científica en personas con discapacidad psíquica o intelectual que no puedan manifestar su voluntad. Lo cual constituye una seria limitación para realizar investigación en personas con daño neurológico, situación que en el pasado se superaba con el consentimiento informado otorgado por un representante legal o apoderado del paciente. Esta situación no sólo preocupa a los Comités de Ética que se han visto en la obligación de rechazar proyectos de investigación en base al artículo 23 de la Ley 20.584 y a los investigadores en neurociencia afectados, sino que también a los propios pacientes quienes a través de sus asociaciones o agrupaciones de enfermos neurológicos y sus familiares (v.gr. portadores de enfermedad de Alzheimer o afectados por enfermedad de Huntington) han expresado públicamente en reunión con representantes de Comités de ética nacionales ${ }^{9}$, su rechazo a esta medida que limitaría la investigación clínica en nuestro país de la enfermedad de la que son portadores, en aquellos que estén en etapas avanzadas de esa enfermedad.

La segunda limitación importante está determinada en el artículo 13 de la Ley 20.584, que establece que quienes no estén directamente relacionados con la atención de salud de la persona no tendrán acceso a la información contenida en la ficha clínica. Entre las excepciones, a este mandato del artículo 13 no se contempla el acceso a la información contenida en la ficha clínica para investigación clínica o epidemiológica. Por lo tanto, el titular de la ficha, o sea, el paciente debería otorgar una autorización notarial para tal fin. Esta limitación si bien es relativa, pues en ciertas circunstancias puede ser posible conseguir la autorización notarial, podría crear en innumerables casos una barrera infranqueable para realizar investigación clínica y epidemiológica, tan necesaria para conocer la realidad clínica y sanitaria de nuestro país. Otra implicancia de esta disposición es la potencial limitación que provocará en la publicación de casos clínicos en revistas biomédicas, que son tan necesarios para el avance de las ciencias médicas y las clínicas. Al alero de este marco legal, los comités editoriales de revistas nacionales podrían exigir para publicar un caso clínico, la autorización del Comité de Ética institucional además de las habituales medidas para proteger el anonimato del paciente, cuyo caso es presentado. 
Los artículos de la ley, requieren de una interpretación inserta en el conjunto del ordenamiento jurídico, con el objeto de evitar que una interpretación literal de la ley, sin una visión integradora del ordenamiento jurídico vigente, pueda llevar a que los derechos de quienes requieren una especial protección sean privados, perturbados o amenazados, en el legítimo ejercicio de sus derechos. De ahi la necesidad de garantizar que las acciones de salud sean las adecuadas para las necesidades del país y de toda su población, asegurando la participación de todas las personas, de manera libre, igualitaria y digna, mediante el debido ejercicio de los derechos y adecuado resguardo de quienes participan en investigación cientifica, que entregue garantías de la protección de la salud y de la reparación del daño.

En conclusión, es justo reconocer que nuestro país cuenta con un cuerpo de normas legales cuyo espíritu es proteger adecuadamente a la población en acciones de salud y que además otorga un marco de referencia legal a quienes participan en la investigación cientifica con seres humanos. Sin embargo, existen algunos aspectos puntuales en la nueva ley que deben ser aclarados y/o eventualmente modificados, atendiendo al espiritu con que fue formulada la Ley 20.584. En este sentido creemos que todas las instituciones involucradas en investigación cientifica en seres humanos: universidades, sociedades cientificas, academias del Instituto de Chile y CONICyT deberian representar a los poderes del Estado estas limitaciones puntuales a fin de perfeccionar los cuerpos legales que rigen o tienen injerencia en la investigación Biomédica en Chile.

Gina G. Raineri B. * y Manuel Oyarzún G. ** *Abogado y Enfermera-Matrona. Magíster en Bioética. Profesora asistente y miembro del Comité de Ética de Investigación en Seres Humanos, Facultad de Medicina, Universidad de Chile. ** Profesor titular y Presidente, Comité de Ética de Investigación en Seres Humanos, Facultad de Medicina, Universidad de Chile.

\section{Bibliografía}

1.- GOBIERNO DE CHILE. Ley 20.584 Sobre derechos y deberes de los pacientes en su atención en salud. 13 de Abril, 2012.

2.- SOTOMAYOR M A. Algunas consideraciones en torno a la bioética y a la investigación científica biomédica. Rev Chil Enf Respir 2007; 23: 7-10.

3.- REAL ACADEMIA ESPAÑOLA. Diccionario de la Lengua Española. 21 a edición, Espasa Calpe S.A. Madrid. 1998.

4.- GOBIERNO DE CHILE. Ley 20.120 Sobre la investigación científica en el ser humano, su genoma y prohíbe la clonación humana. 7 de Septiembre 2006.

5.- SUBSECRETARÍA DE SALUD PÚBLICA. Minsal. Reglamento 114. Aprueba Reglamento de la Ley 20.120 .
6.- RAINERI G. Cobertura mediante seguros del eventual daño a la salud en los sujetos que participan en ensayos clínicos multicéntricos de investigación en Chile. Tesis para optar al grado de Magister en Bioética. Facultad de Medicina, Universidad de Chile, 2009.

7.- EMANUEL E J, WENDLER D, GRADY C. What makes clinical research ethical? JAMA 2000, 283: 2701-11.

8.- O'RYAN M. Investigación médica en Chile a la luz de la nueva legislación. Rev Chil Infectol 2013; 1: 7-9.

9.- GUARDA E, KALTWASSER G, SANTOS M, SHAND B, VILLAGRÁN A. $3^{\text {er }}$ Curso de Bioética en investigación: Problemas éticos frecuentes en investigación en seres humanos. Comité de ética en Investigación de la Escuela de Medicina y Centro de Bioética. Pontificia Universidad Católica de Chile. 16 de Noviembre, 2012. 